\title{
KARAKTERISTIK FISIKOKIMIA SERBUK JAMU DAUN BELUNTAS (Pluchea indica L.)
}

Physicochemical Characteristics of Beluntas Leaves Herb Powder (Pluchea indica L.)

\author{
Dikky Akhirta Rochman ${ }^{1}$ Eko Sutrisno ${ }^{2}$ dan Atmiral Ernes ${ }^{2}$ \\ ${ }^{1}$ PT. Multi Bintang Indonesia Mojokerto Jawa Timur \\ ${ }^{2}$ Fakultas Teknik Prodi Teknologi Hasil Pertanian Universitas Islam Majapahit \\ Email: ekosudrun@yahoo.com
}

\begin{abstract}
ABSTRAK
Penelitian ini bertujuan untuk mengetahui karakteristik fisikokimia serbuk jamu dari bahan daun beluntas (Pluchea indica L.). Serbuk jamu daun beluntas dibuat dengan perbandingan daun beluntas : asam jawa yaitu 9:1, 8:2, 7:3. Serbuk daun beluntas dianalisis karakteristik fisikokimia yang meliputi: waktu larut dalam air, bagian tidak larut air, kadar air, aktifitas Vitamin C dan pH. Hasil penelitian menunjukkan bahwa waktu larut serbuk jamu daun beluntas dalam air rata-rata 92 detik, bagian tidak larut air sebesar 7,87 \%, kadar air rata-rata 0,84 \%, aktifitas Vitamin C rata-rata sebesar 2,53\% dan pH 4,59.
\end{abstract}

Kata kunci: Daun beluntas, serbuk jamu, sifat fisikokimia

\section{ABSTRACT}

This study aims to determine the physicochemical characteristics of herb powder from beluntas leaves (Pluchea indica L.). Beluntas leaves herb powder is made by proportion of beluntas leaves : tamarind which is 9:1, 8:2, 7:3. Beluntas leaves herb powder was analyzed by physicochemical characteristics which include: time dissolved in water, insoluble parts of water, water content, activity of Vitamin $C$ and $\mathrm{pH}$. The results of the study showed that the dissolved time of beluntas leaves herb powder in water averaged 92 seconds, the water insoluble part was $7.87 \%$, the water content averaged $0.84 \%$, Vitamin $C$ activity averaged $2.53 \%$ and $\mathrm{pH} 4.59$.

Keywords: Beluntas Leaves, Herb Powder, Physicochemical Characteristics

\section{PENDAHULUAN}

Masyarakat Indonesia umumnya memanfaatkan tanaman beluntas (Pluchea indica L.) sebagai lalapan dan obat tradisional (Suseno, 2013) dalam bentuk jamu. Manfaat daun beluntas antara lain untuk menghilangkan bau badan, turun panas, batuk, diare, meningkatkan nafsu makan, membantu pencernaan, rematik dan nyeri persendian (Winarno dan Sundari, 1998; Susetyarini, 2007; Yuniarti, 2008). Pada bagian daun beluntas terkandung alkaloid, tanin, minyak atsiri, dan flavanoid (Hariana, 2006). Dalimartha (1999) menjelaskan bahwa daun beluntas mengandung asam chlorogenik, natrium, alumunium, kalsium, magnesium, fosfor, lemak, besi, amino, vitamin $\mathrm{A}$ dan $\mathrm{C}$ sehingga dapat dimanfaatkan sebagai antioksidan (Tampubolon, 1995; Muhlisah, 2008; Widyawati, 2004; Andarwulan et al., 2008).

Gaya hidup masyarakat yang semakin modern menuntut adanya produk yang praktis. Pembuatan jamu daun 
beluntas dalam bentuk serbuk merupakan salah satu solusi dalam pemanfaatan daun beluntas. Harianto (2015) melakukan pengemasan bubuk daun beluntas ke dalam kantong teh dengan penambahan bahan berupa lemon. Keuntungan bentuk serbuk yaitu daya simpan yang lama, mudah larut dalam air, memudahkan cara penyajian, praktis dan mudah dibawa (Hartomo dan Widiatmoko, 1993; Deasy, 2003 dan Angria, 2011). Bentuk bubuk dapat menurunkan biaya produksi serta mampu mempertahankan zat gizi seperti mineral dan vitamin yang mudah rusak apabila dalam bentuk cair (Winarno, 2004). Berdasarkan hal tersebut, maka penelitian ini bertujuan untuk mengetahui karakteristik fisikokimia serbuk jamu dari bahan daun beluntas (Pluchea indica $\mathrm{L}$ ).

\section{METODE}

\section{Bahan dan Alat}

Bahan yang digunakan dalam penelitian ini, meliputi daun beluntas, asam jawa, kunyit, dextrin 10\%, putih telur, $\mathrm{CMC}$, air, $\mathrm{NaCl}$, gula, aqudes dan iodium. Alat yang digunakan antara lain: oven, blender, $\mathrm{pH}$ meter, gelas ukur, termometer, panci, pisau, pengaduk, kompor, ayakan 100 mesh, stopwatch, timbangan digital, tabung reaksi, desikator dan plastik HDPE.

\section{Prosedur pembuatan serbuk jamu daun beluntas dan asam jawa}

Dipilih daun beluntas yang belum terlalu tua. Jamu daun beluntas dibuat dengan perbandingan beluntas dan asam jawa yaitu 9:1, 8:2 dan 7:3. Daun beluntas, kunyit dan asam jawa dicuci selanjutnya ditimbang. Tiap perlakuan ditambahkan air $500 \mathrm{ml}$ selanjutnya diekstrak selama 5 menit. Setelah disaring tiap perlakuan ditambahkan dekstrin 10\%, Putih telur 30\%, CMC 0,5 $\%$, gula $10 \%$ dan $\mathrm{NaCl} 1 \%$, kemudian dimixer hingga bentuknya seperti busa. Dituangkan ke loyang yang sudah dilapisi plastik High Density Polyethylene (HDPE) sebanyak $200 \mathrm{ml}$. selanjutnya di oven dengan suhu $60^{\circ} \mathrm{C}$ selama $3-4$ jam, setelah kering di blender drymill hingga berbentuk bubuk. Bubuk yang diperoleh, diayak dengan ayakan ukuran 100 mesh. Bubuk daun bluntas dan asam jawa instan dikemas menggunakan plastik dengan berat $18 \mathrm{gr} /$ kemasan. Satu kemasan disajikan menggunakan air dengan suhu $50^{\circ} \mathrm{C}$ sebanyak $150 \mathrm{ml}$. Serbuk jamu terbaik diketahui dari karakteristik fisik (waktu larut dalam air, bagian tidak larut air), karakteristik kimia (kadar air, aktifitas Vitamin $\mathrm{C}$ dan $\mathrm{pH}$ ).

\section{Parameter pengamatan}


a. Waktu larut dalam air

Sampel sebanyak $5 \mathrm{~g}$ larutkan dalam $50 \mathrm{ml}$ air, diaduk hingga homogen lalu dicatat berapa lama waktu sampel sampai terlarut sempurna dalam air.

b. Bagian Tidak Larut Air (SNI 01-28911992)

Sampel seberat 5 g masukkan kedalam gelas piala $500 \mathrm{ml}$, ditambahkan 200 $\mathrm{ml}$ air kemudian aduk hingga larut. Setelah itu tuang ke dalam kertas saring yang telah dikeringkan dalam oven dan diketahui beratnya. Bilas gelas piala dan kertas saring dengan aquades hingga didapatkan residu pada kertas saring. Keringkan kertas saring dalam oven pada suhu $105^{\circ} \mathrm{C}$ selama 2 jam, dinginkan dalam desikator dan timbang.

Bagian Tidak larut air $=\frac{W 1-W 2}{W 3} \times 100 \%$

Ket:

$\mathrm{W} 1=$ Berat kertas saring kosong $(\mathrm{g})$

$\mathrm{W} 2=$ Berat kertas saring berisi bagian tidak larut air $(\mathrm{g})$

W3 = Berat sampel $(\mathrm{g})$

c. Kadar Air Metode Gravimetri (AOAC dalam Sudarmardji, $d k k, 1997)$

Sebanyak 1 g sampel di oven pada suhu $105^{\circ} \mathrm{C}$ selama 3 jam. Selanjutnya sampel didinginkan dalam desikator dan ditimbang hingga bobotnya konstan.

Kadar Air $(\%)=\frac{B 1-B 2}{B 1} \times 100 \%$

Ket:

B1 = Bobot awal (g)

B2 = bobot akhir $(\mathrm{g})$

d. Vitamin C metode Titrasi (FI IV, 1995)

Sampel seberat 0,05 gram dianggap sebagai berat awal, dimasukkan dalam labu ukur $250 \mathrm{ml}$, ditambahkan 10

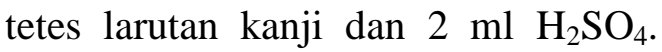
Kemudian ditambahkan aquades sampai $100 \mathrm{ml}$. Sampel dititrasi dengan larutan $I_{2}$ (Iodium) sampai berubah warna menjadi biru violet. Catat volume $\mathrm{I} 2$ yang digunakan.

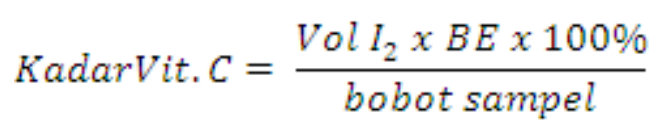

e. $\mathrm{pH}(\mathrm{AOAC}, 1990)$ Larutkan sampel dengan air $50 \mathrm{ml}$. kemudian $\mathrm{pH}$ meter masukkan dalam larutan.

\section{HASIL}

\section{Parameter pengamatan}

a. Waktu larut dalam air 
Hasil pengujian waktu Larut dalam air pada serbuk jamu daun beluntas dapat dilihat dari Tabel 1.

Tabel 1. Waktu larut dalam air serbuk jamu daun beluntas

\begin{tabular}{cc}
\hline Beluntas : Asam Jawa & $\begin{array}{c}\text { Waktu } \\
(\text { detik) }\end{array}$ \\
\hline $9: 1$ & 123 \\
$8: 2$ & 87 \\
$7: 3$ & 66 \\
\hline
\end{tabular}

b. Bagian Tidak Larut Air (SNI 01-28911992)

Hasil pengujian bagian tidak larut air pada serbuk jamu daun beluntas dapat dilihat pada Tabel 2.

Tabel 2. Bagian tidak larut air serbuk jamu daun beluntas

\begin{tabular}{cc}
\hline Beluntas : Asam Jawa & $\begin{array}{c}\text { Bagian tidak } \\
\text { larut air }(\%)\end{array}$ \\
\hline $9: 1$ & 10 \\
$8: 2$ & 7,8 \\
$7: 3$ & 5,8 \\
\hline
\end{tabular}

c. Kadar Air Metode Gravimetri (AOAC dalam Sudarmadji, 1997)
Hasil pengujian kadar air pada minuman serbuk jamu daun beluntas dapat dilihat pada Tabel 3.

Tabel 3. Kadar air serbuk jamu daun beluntas

\begin{tabular}{cc}
\hline Beluntas : Asam Jawa & $\begin{array}{c}\text { Kadar Air } \\
(\%)\end{array}$ \\
\hline $9: 1$ & 0,81 \\
$8: 2$ & 0,84 \\
$7: 3$ & 0,87 \\
\hline
\end{tabular}

d. $\mathrm{pH}(\mathrm{AOAC}, 1990)$

Hasil pengujian pH serbuk jamu daun beluntas disajikan pada Tabel 4 .

Tabel 4. pH serbuk jamu daun beluntas

\begin{tabular}{cc}
\hline Beluntas : Asam Jawa & $\mathrm{pH}$ \\
\hline $9: 1$ & 5,27 \\
$8: 2$ & 4,47 \\
$7: 3$ & 4,03 \\
\hline
\end{tabular}

e. Kadar Vitamin C

Hasil pengujian kadar vitamin $\mathrm{C}$ serbuk jamu daun beluntas ditunjukkan pada Tabel 5 berikut.

Tabel 5. Kadar vitamin C serbuk jamu daun beluntas

\begin{tabular}{cc}
\hline Beluntas : Asam Jawa & $\begin{array}{c}\text { Vitamin C } \\
(\%)\end{array}$ \\
\hline $9: 1$ & 1,76
\end{tabular}




\begin{tabular}{ll}
\hline $8: 2$ & 2,34 \\
$7: 3$ & 3,50 \\
\hline
\end{tabular}

\section{PEMBAHASAN}

Kadar air pada daun beluntas mempengaruhi kelarutannya. Daun beluntas massanya rendah dan banyak mengandung serat sehingga bahan tambahannya tidak boleh terlalu banyak, seperti dekstrin (Stephen, 1995). Keadaan tersebut karena bahan cenderung lengket, tidak mampu menyerap air dengan baik serta sulit menyebar dalam air (Straatsma, et al., 1999). Oleh sebab itu hasil pengujian waktu larut dan bagian tidak larut air pada minuman beluntas serbuk yang disajikan pada Tabel 1 dan Tabel 2 pada hasil perbandingan daun beluntas : asam jawa $9: 1$, waktu larut dan bagian tidak larut air paling tinggi dibandingkan dengan perlakuan lainnya, yaitu dengan waktu larut 123 detik dan bagian tidak larut air sebesar 10\%. Daun beluntas juga mengandung senyawa tannin, alkaloid dan steroid yang dapat menjadi endapan jika larut dalam air (Minhatun dan Tukiran, 2017).

Bahan pengisi yang digunakan dalam penelitian yaitu dekstrin $10 \%$ dan putih telur $30 \%$ dengan takaran yang sama sehingga kadar air dalam tiap perlakuan hampir sama yang dapat dilihat pada Tabel 3. Putih telur berfungsi sebagai pembuih dan untuk mempercepat pengeringan (Albab dan wahono, 2016). Penggunaan asam jawa sebagai bahan campuran sangat mempengaruhi $\mathrm{pH}$ larutan (Tabel 4), karena daging buah asam jawa mengandung $8-14 \%$ asam tartarat (Rukmana, 2005). Penggunaan oven mempengaruhi kadar vitamin $\mathrm{C}$ pada bahan (Tabel 5), karena Vitamin C sangat sensitif dan mudah rusak jika terjadi perubahan suhu, cahaya, enzim, oksigen, dan katalisator logam (Suntornsuk, et.al. 2002).

\section{KESIMPULAN}

Waktu larut air dan bagian tidak larut air terbaik didapatkan dari perbandingan daun beluntas : asam jawa 7 : 3, dengan nilai waktu larut 66 detik dan ketidak larutan dengan nilai 5,8\% dengan kadar vitamin $\mathrm{C}$ tertinggi 3,50\%. Untuk hasil pengujian kimia data terbaik didapatkan dari perbandingan daun beluntas : asam jawa $9: 1$ dengan kadar air $0,81 \%$ dengan $\mathrm{pH} 5,8$.

\section{SARAN}

Diperlukan penelitian lebih lanjut untuk menentukkan proporsi perbandingan dan perlakukan yang baik 
agar minuman instan memiliki nilai gizi yang baik dan dapat diterima oleh lapisan masyarakat

\section{UCAPAN TERIMAKASIH}

Penulis mengucapkan terima kasih kepada dosen dan tim lab prodi THP FT Unim yang telah membantu penulis selama melakukan penelitian.

\section{DAFTAR PUSTAKA}

Albab, S. U dan Wahono, H. S. 2016. Pengaruh Proporsi Mocaf dengan Ubi Jalar Oranye dan Penambahan Baking Powder Terhadap Sifat Kerupuk Cekeremes. J. Pangan dan Agroindustri Vol. 4 (2) hal: 515-524

Andarwulan, N., R. Batari, D.A. Sandrasari dan H. Wijaya. 2008. Identifikasi Senyawa Flavonoid Dan Kapasitas Antioksidannya Pada

Ekstrak Sayuran Indigenous Jawa

Barat. Makalah Seminar pada Half Day Seminar on Natural Antioxidants: Chemistry,

Biochemistry and Technology. Bogor, 16 September 2008. Biopharmaca Research CenterSEAFAST Center, Institut Pertanian Bogor, Bogor.
Angria, M. 2011. Pembuatan minuman instan pegagan (Centella asiatica) dengan citarasa cassia vera. Skripsi. (tidak dipubliksikan) Fakultas Teknologi Pertanian. Universitas Andalas Padang.

AOAC. 1990. Official Methods of Analysis. Association of Official Analytical Chemist. USA: Washington DC.

Dalimartha, S. 1999. Atlas Tumbuhan Obat Indonesia. Trubus Agriwidya. Jakarta.

Deasy, W. 2003. Proses Produksi dan Karakterisasi Tepung Biji Mangga Jenis Arumanis (Mangifera indica L.). Skripsi (tidak dipublikasikan) Teknologi Industri Pertanian. Fakultas Teknologi Pertanian. Institut Pertanian Bogor. Bogor

Hariana, A. 2006. Tumbuhan Obat dan Khasiatnya. Seri 1. Penebar Swadaya. Jakarta.

Harianto, I. 2015. Pengaruh Konsentrasi Tepung Daun Beluntas (Pluchea Indica Less) Terhadap Sifat Fisikokimia, Organoleptik, dan Aktivitas Antioksidan pada Minuman, Skripsi (tidak dipublikasikan). 
Fakultas Teknologi Pertanian.

Universitas Kristen Widyamandala

Surabaya.

Hartomo, A. J. dan M. C. Widiatmoko.

1993. Emulsi dan Pangan Instan

Berlesitin. Andi Offset. Yogyakarta.

Minhatun, N. dan Tukiran. 2017. Uji Antioksidan Dan Identifikasi

Senyawa Aktif Dari Ekstrak

Kloroform Daun Tanaman Beluntas

(Pluchea indica L.). UNESA Journal

of Chemistry, Vol. 6, No. 2, hal: 107

-112 .

Muhlisah, F. 2008. Tanaman Obat Keluarga. Penebar Swadaya. Jakarta.

Rukmana, R. 2005. Rumput Unggul Hijauan Makanan Ternak. Kanisius. Yogyakarta

Stephen, M. 1995. Food Polysaccharides and Their Applications. Marcell Dekker, Inc., South Africa

Straatsma J, Van Houwelingen G, Steenbergen AE, De Jong P. 1999. Spray Drying of Food Products: 2. Prediction of Insolubility Index. J Food Eng. 42 (2) hal: 73-77

Sudarmardji, S. Haryono dan Suhardi. 1997. Prosedur Analisa untuk Bahan
Makanan dan Pertanian. Edisi Ketiga. Liberty . Yogyakarta.

Suntornsuk, L., W. Kritsanapun, S. Nilkamhank, and A. Paochom. 2002. Quantitation of vitamine C content in herbal juice using direct titration. J. of Pharmaceutical and Biochemical Analysis, 28: 849-855.

Suseno, M. 2013. Sehat dengan Daun. Buku Pintar, Yogyakarta.

Susetyarini, E. 2007. Pengaruh Dekok Daun Beluntas (Pluchea indica Less) Pada Terhadap LD 50 (Toksisitas Akut) Tikus Putih Jantan (Ratus nurwegicus). Laporan Penelitian. Lemlit UMM.

Tampubolon, 1995, Mengembangkan Minat dan Kebiasaan Membaca pada Anak, Bandung: Angkasa

Widyawati, P. S., Wijaya, C. H., Harjosworo P. S., dan Sajuthi, D., 2004. Pengaruh Ekstraksi dan Fraksinasi terhadap kemampuan menangkal radiakl bebas Dpph $(1,1-$ Difenil-2-Pikrilhidrazil) ekstrak dan Fraksi Daun Beluntas (Plucheu indica (L.) Less). Seminar Rekayasa Kimia dan Proses. 2010. ISSN: 1411 - 4216 
Winarno, F. G. 2004. Kimia Pangan dan

Gizi. Gramedia Pustaka Utama.

Jakarta

Winarno, M. Wien dan D. Sundari. 1998.

Pemanfaatan Tumbuhan Sebagai

Obat Diare di Indonesia. Pusat

Penelitian dan Pengembangan

Farmasi Balai Penelitian dan

Pengembangan Kesehatan

Departemen Kesehatan RI. Jakarta.

Yuniarti, T. 2008. Ensiklopedia Tanaman

Obat Tradisional, Cetakan Pertama.

MedPress. Yogyakarta 